ment and personnel at his disposal. At least observations of potential-gradient and conductivity (preferably both positive and negative) should be made.

(4) Meteorological observations in accordance with the observer's equipment should be made at convenient periods (as short as possible) throughout the interval. It is suggested that at least temperature should be read every fifth minute (directly after the magnetic reading for that minute).

(5) Observers in the belt of totality are requested to take the magnetic reading every thirty seconds during the interval, ten minutes before and ten minutes after the time of totality, and to read temperature also every thirty seconds before the magnetic readings.

It is hoped that full reports will be forwarded as soon as possible for publication in the journal Terrestrial Magnetism and Atmospheric Electricity. Those interested are referred to the results of the observations made during the solar eclipse of June 8 , 1918, the publication of which was begun in the September (1918) issue of the journal. A summary of the results obtained is given in the March (I919) issue.

Louis A. BAuER.

Carnegie Institution of Washington, Department of Terrestrial Magnetism, Washington, D.C., February I5.

\section{A Proof that any Aggregate can be Well-ordered.}

AlL the critics of my method sketched or described in my two letters to NATURE (vol. ci., pp. 84 and 304 , I9I8), in my two notes in Comptes rendus (vol. clxvi., pp. $5^{20-23}$ and 984-86, I9I8), in Mind for July, 1918, and in Science Progress for October, 1918, wish to see a certain particular case solved in detail. Although this case does not throw so much light on the problem as the equally simple method of dealing with the general case, which I happen to have discovered long before I applied it to special cases, I here give the treatment of the particular case referred to.

Suppose that an aggregate $\mathbf{M}$ is such that there are classes $x_{1}, x_{2} \ldots$., where $x_{n}$ is the class of all those chains of $\mathbf{M}$ of type $n$, and the suffixes of the $x$ 's are all the finite ordinal numbers (that is, those less than $\omega)$; we are to prove that $M$ has a chain of type $\omega$. We will define by complete induction a rule for actually constructing out of the $x$ 's many (we can prove afterwards that the many are all; we do not, of course, merely postulate that there is a non-null class of all such classes) classes of direct continuations of which each contains one chain from each $x$. The rule, though it is, accordingly, split into two parts, is to be regarded as one whole; and it can be so regarded, since it does not involve an infinity of arbitrary selections.

(I) With each member $\mathrm{K}_{2}$ of $x_{2}$, class that member of $x_{1}$ which is the sole segment of $K_{2}$. Thus each member of $x_{1}$ is classed with many of $x_{2}$, and each member of $x_{2}$ is classed with a definite one of $x_{1}$ so that together these members form a class of direct continuations with members of types $I$ and 2 .

(2) In general, for $2<n<\omega$, with each member $\mathrm{K}_{n}$ of $x_{n}$ classify $(a)$ that member $\left(\mathrm{K}_{n-1}\right)$ of $x_{n-1}$ which is a segment of $\mathrm{K}_{n}$, and (b) also those chains of types $n-2, \ldots 2$, I previously classed with $\mathrm{K}_{n-1}$ by the rule. Remember not to regard here a class of $y$. and $z$ as anything more than just $y$ and $z$. For instance, each member of $x_{3}$ forms, with the chains classed with it, a class of direct continuation with three members; and we easily see that, in general, every class of direct continuations with $n$ members is added to, provided that the whole rule is applied and not merely a part of it which stops at $n$.

Thus we have defined a means of rearranging all

$$
\text { NO. } 2577 \text {, VOL. IO3] }
$$

the members of all the $x$ 's so that they form classes of direct continuations of the kind we wished and stated above. Since any class of direct continuations which is formed from the members of $M$, and contains chains of all types less than $\omega$, plainly defines a chain of type $\omega$, each of the classes of direct continuations formed by the rule defines a chain of type $\omega$. This is what we had to prove. We have, indeed, a set of classes of direct continuations such that each class has at least two terms, and, if it has $n$ terms, it has $n+1$.

The Bourne, Basingbourne Road, Fleet, Hants, March ir.

\section{Coal in Thrace.}

Antigonos, a Greek writer about the beginning of our era, made a collection of the accounts of the natural wonders of his time. Among them he mentions-I translate from the Greek edition of 1568 that "they say that in the wild (uncultivated) region of Thrace there is a river called Pontos, which brings down in its course stones resembling anthrax (charcoal), and that these burn, but differ in combustion from charcoal, inasmuch as the use of bellows extinguishes the fire. On the other hand, sprinkled with water they burn all the better." Where was this river? Kiepert does not mention it, but it seems to have flowed into the Black Sea, then called Pontos. It would be interesting to know if anthracite has been found so near Constantinople.

8o Eccleston Square, S.W.r, February 27

THERE is no warranty for suggesting that "stones resembling anthrax" are anthracite; they are far more likely to have been bituminous coal or lignite, both of which burn more readily than does anthracite, which latter is decidedly difficult of ignition. Whilst European Turkey has not been fully explored for coal, the existence of coal is known in various places; a bituminous coal-seam is reported near Keshan, in the province of Adrianople, and along parts of the northern coast of the Sea of Marmora and there are lignite deposits known near Rodosto, near Dedeagatch, and even within a short distance of Constantinople. Obviously any of these deposits might have given rise to the stones referred to by Canon M'Clure.

It would be interesting to know whether the Greek text excludes the possibility of its reference being to the district of Pontos, on the south shores of the Black Sea, as the best-known coal-mines of all the region are those to the south of Heraclea in that district.

Armstrong College, Newcastle-upon-Tyne,

$$
\text { March } 3 .
$$

HENRY Lours.

\section{Curious Markings on Chalk.}

Dr. Andrews (Nature, March 13, p. 25) probably knows more about the natural forms assumed by chalk than I do, but I think, nevertheless, that the specimen described by me in the February issue of Man (p. I7, pl. B) cannot be disposed of quite so summarily as he supposes. And I would suggest that it is generally considered unwise, in such matters, to publish a definite opinion before an examination of the actual specimen has been made.

It is my hope that before long $\mathrm{Mr}$. GathorneHardy may exhibit his discovery at a meeting of 